\title{
STUDENTS' GRAMMAR AND SENTENCE STRUCTURE OF THE TEXTS WRITTEN IN PARAGRAPH WRITING CLASS
}

\author{
Aisyah Ririn Perwikasih Utari \\ Universitas Muria Kudus, Indonesia
}

\begin{abstract}
Writing a text becomes the last skill in English learning. It needs a productive creativity and ability of the language used in it. The learners should listen, speak, read, and write to prove that they can use English well. Paragraph Writing is the first writing subject in the curriculum of English Education Department which should be taken by the students who are in the second semester. The activities of writing cover some processes in which they should know and apply the theories to practice writing some texts. Grammar and sentence structure are the crucial problems faced by the students. It needs an extra attention to make them understand about the components involved in this element of writing. The components are applied step by step from the beginning of the semester until it ends. The research problems are raised with some questions as follows: (1) what are the grammar and sentence structure's components of the students' text in Paragraph Writing class? ; (2) How is the analysis of grammar and sentence structure of the students' text in Paragraph Writing class?. Further chapter of the research will provide the analyzed data and the result as the answer of the problems raised.The texts written by the students as the data source are randomly chosen from the whole final projects. From the result of the analysis, it can be found that $63 \%$ of the total texts are grammatically incorrect. The components of grammar structure are also recorded that there are $10 \%$ of the sentences are stringy, $5 \%$ comma splice, $10 \%$ run-on sentence, and $12 \%$ sentence fragment. Mostly, the problem that the students face are about concidering the tense and verb words. The conjunctions that influence the meaning are also mostly mis-used. The percentages found in the analysis show that most of the students make some errors in their grammar use in writing their paragraph writing project. The suggestions of the correct ones are also written in their text sheets to make further revisions. This can make them concern more to learn from the analysis. Paragraph writing class is like a stepping stone for them to start learning from mistakes.
\end{abstract}

Key words: Grammar and sentence structure, Paragraph Writing

\section{INTRODUCTION}

Writing in English should not be a difficult thing anymore for university level students. It becomes a crucial thing when they decided to join a language department such as English Education Department of Muria Kudus University. One of the various subjects of the curriculum in the second semester is Paragraph Writing. It is considered as a starting point of making writing in English as their habit. How to write a text with correct sentence structure is a crucial thing to do, because the purpose of writing is making the message from the writer to the reader successfully sent appropriately without significant misunderstanding and ambiguity.

Sentence is the basic part of forming a good paragraph of a text. Every single sentence plays its important roles to the whole message, especially for written text. This means a meaningful sentence will be based on its structure, whether it is correct or incorrect. The art 
of a language is on its structure. In written text, readers can only focus on the text they read, without being able of making a direct clarification like in a spoken text or a conversation. This should be known by writers; clear things are provided to be interpreted by readers.

Students who join the paragraph writing class intend to know the importance of writing in a good sentence structure. A brilliant and intense idea can be an additional awesome combination of a text. It will break the assumption of ignoring grammar in English learning. Despite having the productive knowledge of vocabulary required at the level as well as their better fluency in grammar, they still have problems in writing (Seyabi and Tuzlukova, 2014: 38). Learning focus on grammar and sentence structure are not only provided and discussed in Grammar class, but it is also considered to be presented intensively in writing class, especially Paragraph Writing to begin their experience of writing good text in good structure and organization. They should learn the components of good grammar and sentence structure in which they can make it as the key to lead them write a good text.

Grammar is often defined as the rule system of a language, but it is also useful to think of it as a resource for expressing meaning (Lynch and Anderson, 2013:4). The components of grammar and sentence structure in writing a good paragraph can be described as follows: the paragraph has correct verb tenses; the paragraph has the correct use of subjectverb agreement, the paragraph has a correct use of articles (a, the); the paragraph has the correct use of pronoun agreement, the paragraph has no choppy sentences; the paragraph has no stringy sentences, the paragraph has no sentence fragment, the paragraph has no run-on sentences/comma splices.

Writing a text with such components of grammar and sentence structure should be done by the students in every meeting. They have to create one text in every meeting, with peer's and lecturer's review. It is expected that there will be a final writing project in which it will be considered as the masterpiece of their portfolio in Paragraph Writing Class. Analyzing those masterpieces will be a very interesting thing to know how they follow the rules of components of grammar and sentence structure and whether they make a successful writing project or not. They are expected to learn to recognize and correct some common errors in sentence structure (Oshima and Hogue, 1998: 172).

The final project is chosen to be analyzed because all of the materials of grammar and sentence structure are discussed and they have followed all of the process of paragraph writing. The main purpose of this research is to analyze the grammar and sentence structure of the final writing project done by the students in Paragraph Writing class of English Education Department of Muria Kudus University.

To mention the problem statements of the research clearly, there are some points can be written, as follows: (1) What are the grammar and sentence structure's components of the students' text in Paragraph Writing class?; (2) How is the analysis of grammar and sentence structure of the students' text in Paragraph Writing class? In line with the statements of the problem, there are some objectives of the research to answer the problems raised: (1) To find out the grammar and sentence structure components of the students' text in Paragraph Writing class; (2) To explain the analysis of grammar and sentence structure of the students' text in Paragraph Writing class. The research significance is mainly described theoretically in contributing the theories of writing good paragraph in organized components of grammar and sentence structure is mainly proposed by this research. It will enrich the source of readers who want to find out any matters of Paragraph Writing. While practically, the review and analysis can lead the readers who can be a student, teacher, lecturer, and even a researcher to make a further understanding and continuing activity to apply the same way as what this research contributes and conducts. 
To avoid an overlapping discussion of the research, some consideration of scope and limitation are provided. It is limited to the analysis of the texts in which they are written by the students in Paragraph Writing class as the final project in the end of the second semester of English Education Department in Muria Kudus University. The analysis itself focuses on the components of grammar and sentence structure which are mentioned in the background of the research and will be discussed further in reviews of related literature in this research.

\section{REVIEW OF RELATED LITERATURE}

This point is proposed to discuss the reviews of related literature in which it consists of some subchapters as follows: Paragraph Writing Class, Grammar and sentence structure, Previous Research, and Theoretical Framework.

\section{Paragraph Writing Class}

The subject of Paragraph Writing is available in the second semester of the latest curriculum of English Education Department of Muria Kudus University. It provides the starting point to practice the students' writing skill intensively in 4 credits or about 3 and a half of hour. The lecture is started with the activity of writing some good sentences before organizing them into a good paragraph. Because the essential thing of writing a good sentence is its grammar and sentence structure, the students are lead to step to learn the components which become the requirements of correct grammar and sentence structure.

The students are commonly incapable of expressing themselves in a clear, correct and comprehensible manner in writing (Alfaki, 2015: 41). Those requirements can be supported in good abilty to construct the sentence using correct grammar and structure. Learning grammar is not only done in grammar class which is also provided exclusively by the department for the students to learn it in intensive way, but it is also done in writing class, especially paragraph writing. They still need to focus on the smallest part of an organized paragraph: a sentence. So, it is the exact time to make them learn and practice writing sentences using the requirements of grammar and sentence structure.

Paragraph writing also provides some materials in which the lecturer should convince them that language is meaningless without grammar, the art of language is on its grammar. So, ignoring grammar in speaking or writing in English is a serious problem. This is why the components of sentence and grammar structure should be one of the crucial things to be told to the students. Besides, the activities of peer's and lecturer's reviews will make their learning process perfect.

\section{Grammar and Sentence Structure}

Many writing rubrics are made in order to give score, to analyze, or to simply learn the requirements of writing a good text. Good grammar and sentence structure can produce a text which is easily to understand and it can avoid misunderstanding and ambiguity. The message can be successfully sent from the writer to readers. Grammar is what gives sense to language; sentences make words yield up their meanings (Department for Education and Employment, 2000:7). Grammar is a knowledge which follows intensively the four skills of language; listening, speaking, reading, writing. Writing is the last skill to master because it needs the previous skills to give such an example in producing the perfect one, because it is written and it can spread all over the universe. It is recorded very well on such media both offline and online. This is why the ability of applying the correct grammar and structure is crucial in mastering English, moreover it is a foreign language which has significant difference with Bahasa Indonesia.

The components of sentence and grammar structure are formulated by many writers; one of them is created by Alice Oshima and Ann Hogue (2006). The elements consist of 
format, mechanics, content, organization, and the last one is grammar and sentence structure. Although grammar and sentence structure become the last element, it covers many point of components which demand the perfect requirements of correct grammar and sentence structure. The components are discussed further in the following points:

1. The paragraph has correct verb tenses.

English, alike some other languages, has the particular forms of tense. It shows the time and the action done, whether it is in past or present or future. It is fairly detailed so that the receiver (commonly known as reader or hearer) can easily recognize when the action actually happens. Correct verb tense becomes one of the requirements of good writing because it can show the readers the exact time of the action happens. It also follows the rules of using English in writing a text.

2. The paragraph has a correct use of subject-verb agreement.

In a sentence, subject-verb agreement is crucial to avoid misunderstanding. In a written text, the writer should provide a clear and tidy information if he/she wants to write a long sentence. Correct subject-verb agreement will help the readers to identify the meaning in which the writer expects to tell.

3. The paragraph has a correct use of articles (a, the).

The correct use of articles is essential in English, because it shows whether the matters are already mentioned or know or not. The different usage between article and determiner is also important to be learnt. Article (a) should be used for unknown or unmentioned thing, and determiner (the) should be used for known or mentioned thing. Writing habits can make this ability perfect because it also needs an instinct to differ article and determiner.

4. The paragraph has the correct use of pronoun agreement.

Pronoun agreement sometimes becomes a problem for English as Foreign Language Learners. For a compound complex sentence, it needs an ability of breaking the action or event still in a tidy relation. One of them is using pronoun. Avoiding repetition is also one of the advantages of using pronoun in a sentence. The writer should be able to describe or choose the correct pronoun to give clear information to the readers.

5. The paragraph has no choppy sentences.

Sometimes a writer unconsciously writes short sentences to provide clear information to the readers. He/she considers that the short sentences need to be separated by period or full stop. However, in writing matters, it is called as choppy sentence. Choppy sentences are often written in the beginning of a text. Because the writer wants to introduce the things he/she wants to write. Too many choppy sentences in a text will show that the text is not sophisticated.

6. The paragraph has no stringy sentences.

A stringy sentence often happens when a writer forgets or does not realize that he/she has to add some discourse marker. The discourse marker plays its role as a connector between clauses or ideas. If the connector is missing, then the sentence will be stringy.

7. The paragraph has no sentence fragment.

Unlike a stringy sentence, a sentence fragment happens when the writer uses a connector but there is no clause follows the previous clause. So, the connector is redundant. It is commonly called as an unfinished sentence. The solution provided is deleting the connector and give a period; or continuing the unfinished sentence by adding another clause.

8. The paragraph has no run-on sentences/comma splices.

Run-on sentence or comma splices often happen if the writer thinks that it is no need to add some punctuation between two clauses. However, it is very important to add some punctuation like comma, period, semicolon, or colon. A run-on sentence can make the 
readers confused when they find two clauses with two different ideas within one sentence and without any marker or connector.

\section{Previous Research}

A research about writing problems faced by the students is previously done by Dr. Ibrahim Mohamed Alfaki from Nile Valley Universityy, Sudan. It is entitled "University Students' English Writing Problems: Diagnosis and Remedy". It identifies the errors and mistakes made by the students. They cover various components such as: spelling, punctuation, capitalization, cognitive problems, and so forth. The conclusion of this research is described as follows, usage mistakes and grammar mistakes will eventually disappear if the students read extensively in English.

\section{Theoretical Framework}

Grammar and sentence structure is one of the elements of the requirements of a good writing, especially in paragraph writing. Paragraph Writing is one of the subjects provided in English Education Department of Muria Kudus University latest curriculum which has 4 credits. All of the students who join the class should learn how to write sentences in correct grammar and structure before organizing them into good paragraph.

There are some components from the elements of grammar and sentence structure that should be known and applied by the students in the writing process: the paragraph has correct verb tenses; the paragraph has the correct use of subject-verb agreement, the paragraph has a correct use of articles (a, the); the paragraph has the correct use of pronoun agreement, the paragraph has no choppy sentences; the paragraph has no stringy sentences, the paragraph has no sentence fragment, the paragraph has no run-on sentences/comma splices.

Those elements are used to analyze the final project of the students in Paragraph Writing class because in the final project, they are already involved in all the process of writing in one semester. The result of the analysis will answer the problem statements which are mentioned previously; mainly finding out the grammar and sentence structure of the texts.

\section{METHOD OF THE RESEARCH}

The design of the research is descriptive qualitative research in which it is proposed to find out the grammar and sentence structure of the text written by students in paragraph writing class. Bogdan and Biklen (1992:30) state that one of the characteristics of qualitative research is descriptive. The data collected are mostly in the form of texts or pictures rather than numbers. The procedure of research can produce the descriptive data which is more informative and explicitly representative. The instrument used in the research is field note. The note consists of the components of grammar and sentence structure found in the texts written by the students in Paragraph Writing Class. The source of the data is the final project of the students who join the paragraph writing class in the second semester of English education Department of Muriakudus University. The data are the texts which are being analyzed based on its components of grammar and sentence structure used in each text.The data collecting covers some steps which will be done as follows: (1) Getting permission from the Dean of the Faculty; (2) Applying the writing activities of grammar and sentence structure in paragraph writing class; (3) Asking the students to write a text as the final project of the paragraph writing class. (4) Collecting the data from the students' texts which have been submitted as the final project of paragraph writing class.

The data will be analyzed qualitatively and the steps in analyzing the obtained data are as follows:(1) Describing the components of grammar and sentence structure in the texts; (2) Identifying the each component of grammar and sentence structure found in each text; (3) Explaining how the components of grammar and sentence structure are used in the 
texts.Finding out the analysis and discussion of grammar and sentence structure used in the texts.

\section{FINDING AND DISCUSSION}

The texts written by the students as the data source are randomly chosen from the whole final projects. From the result of the analysis, it can be found that $63 \%$ of the total texts are grammatically incorrect. The components of grammar structure are also recorded that there are $10 \%$ of the sentences are stringy, $5 \%$ comma splice, $10 \%$ run-on sentence, and $12 \%$ sentence fragment.Mostly, the problem that the students face are about concidering the tense and verb words. The conjunctions that influence the meaning are also mostly mis-used.

The texts are well organized in meaning, but the incorrect grammar still cannot be avoided. The number of $63 \%$ of the whole texts are surprisingly found and almost the every single sentence has some words which are mis-used or mis-placed. In correcting and analyzing the texts, the every sentence is listed in the table and analyzed based on the incorrect part by mentioning the suggestion for the students. This can be very effective because they concern to their own writing and try to find out the correct form to make their writing well organized especially in grammar matters. Another point that is least mentioned in the analysis is about parallelism. Students are mostly trapped in combining the different word classes while they consider the sentence parallel. In detail, they oftenly miss the subject of the second clause in the sentence which is not parallel to the former clause. However, if the texts are analyzed and the suggestions are written, the students will make significant progress for their next steps of learning writing.

\section{CONCLUSION}

The percentages found in the analysis show that most of the students make some errors in their grammar use in writing their paragraph writing project. The suggestions of the correct ones are also written in their text sheets to make further revisions. This can make them concern more to learn from the analysis. Paragraph writing class is like a stepping stone for them to start learning from mistakes. Corrections and suggestions are still needed in order to make a good progress for the students' writing quality, especially the next steps of writing after this subject: essay writing. The texts have to be more organized and idea-based, in another meaning, grammar-focus will not be the only one anymore.

\section{REFERENCES}

Alfaki, I. M. (2015). University Students' English Writing Problems: Diagnosis and Remedy. International Journal of English Language Teaching, 3 (3).

Bogdan, C and Biklen, K. 1992. Qualitative Research for Education. Boston: Advision of Sinn and Schuster, Inc.

Department for Education and Employment. (2000). Grammar for Writing. London: Raising Standards.

Lynch, T. and Anderson, K. (2013). Grammar for Academic Writing. University of Edinburgh: English Language Teaching Centre

Oshima, A. and Hogue, A. (1998). Writing Academic English. New York: Longman

Seyabi, F. A. and Tuzlukova, V. (2014). Writing Problems and Strategies: An Investigative Study in the Omani School and University Context.Asian Journal of Social Sciences and Humanities, 3 (4). 
